\title{
The Research of Internet Information Services on the Impact of Tourism Decision-Making
}

\author{
Yan $\mathrm{Liu}^{1 *}$, Qizhi Yang ${ }^{1}$ and $\mathrm{Bo} \mathrm{Pu}^{2}$ \\ ${ }^{1}$ College of Tourism, Sichuan Agricultural University, Chengdu, Sichuan, 611830, China; ${ }^{2}$ School of Economics and \\ Management, Southwest Jiaotong University, Chengdu, 610031, Sichuan, China
}

\begin{abstract}
Along with the popularization of network, travel decisions have been relying more on the network. This article attempted to study, the role of network in the new generation of tourism decision-making and the behavior of tourists and sum up the investigation and analysis of the literature. In addition, , based on the analysis of various factors that affect tourists' travel decisions, the study focussed on analysing the significance of Internet information services and its features with its various influences on tourists' travel decisions along with the evaluation of the intensity of the effect of each impact factor. This article attempted to explain the relationship between Internet tourism information service and tourists travel decisions, and the impact of the development in the Internet tourism information service on tourism. The study on the marketing and tourism companies has practical significance. It was concluded that information on travel websites in China should be organized in such a way as to attract more tourists, and to have good viewership and therefore productive values. . This article can provide useful suggestions for tourism enterprises, tourism operators and tourists and can also enlighten them.
\end{abstract}

Keywords: Internet, online travel and tourism industry, travel decisions, travel information service.

\section{INTRODUCTION}

With the rapid development in Internet, people can transfer useful information at a faster rate through the network. This has made people to pursue personalized tourism and travel through the best medium. The Internet is most widely used by Chinese media channels which is an efficient way of providing information through media. Therefore, travel agencies in China, need traditional media channels for strengthening tourist's attractions, and also need to explore new media channels throughthe Internet [1].

Network tourism information is characterized by low cost, wide coverage, and comprehensive functions. The use of flexible characteristics has increasingly become the most important travel information source, and has gradually attained a dominant position. Tourists can spend a little time, in order to lower the cost of travel destination on the Internet and can access all kinds of information related to tourism, including the normal competitive price, the reliability of the travel company in the past, etc., and, can realize the information symmetry to a certain extent [2-8]. Therefore, the Internet has reduced the dependence on the traditional tourism market information, and tourists travel decision-making plays an important role.

According to the latest report of Nielsen monitoring Chinese citizens' outbound tourism, the Internet was observed to be the main medium of providing travel information to the Chinese travellers. Due to the rapid development in Internet

*Address correspondence to this author at the College of Tourism, Sichuan Agricultural University, Chengdu, Sichuan, 611830, China;

E-mail: hatk357@163.com and its powerful influence, the Internet has changed the society and people's life. From the perspective of tourism industry, there is a need of further research on the effects and role of Internet on travel decisions.

\section{RELATIVE BASIC THEORY}

\subsection{Tourism Psychology Theory}

Tourism psychology is a new discipline aimed at analysing travel and tourism industry from the psychological perspective, and also studies the role of human behavior in tourism activities, mainly including tourism consumer behavior, tourism service behavior and consumer psychology [9].

Foreign scholars began research on this field in the late 1970s, and the Chinese scholars also began research in the mid-80s to promote tourism psychology teaching and scientific research. Research on tourism psychology was based on two ideas; one is based on travel consumers, and studies the general rule of tourists spending behavior. In addition, it also involves the study of the interaction between tourism workers and tourists. The latter is based on the theory of interaction analysis. In-depth analysis was carried out on the interpersonal relationships in the tourism industry. This paper focused on these two ideas, and conducted research on the general regularity of tourist behavior and tourist motives and their influence on travel behaviour.

\subsection{Consumer Decision-Making Factors Theory}

Consumers purchase choice is mainly influenced by four psychological factors: motivation, perception, learning, beliefs and attitudes. In order to determine the motivation, the 


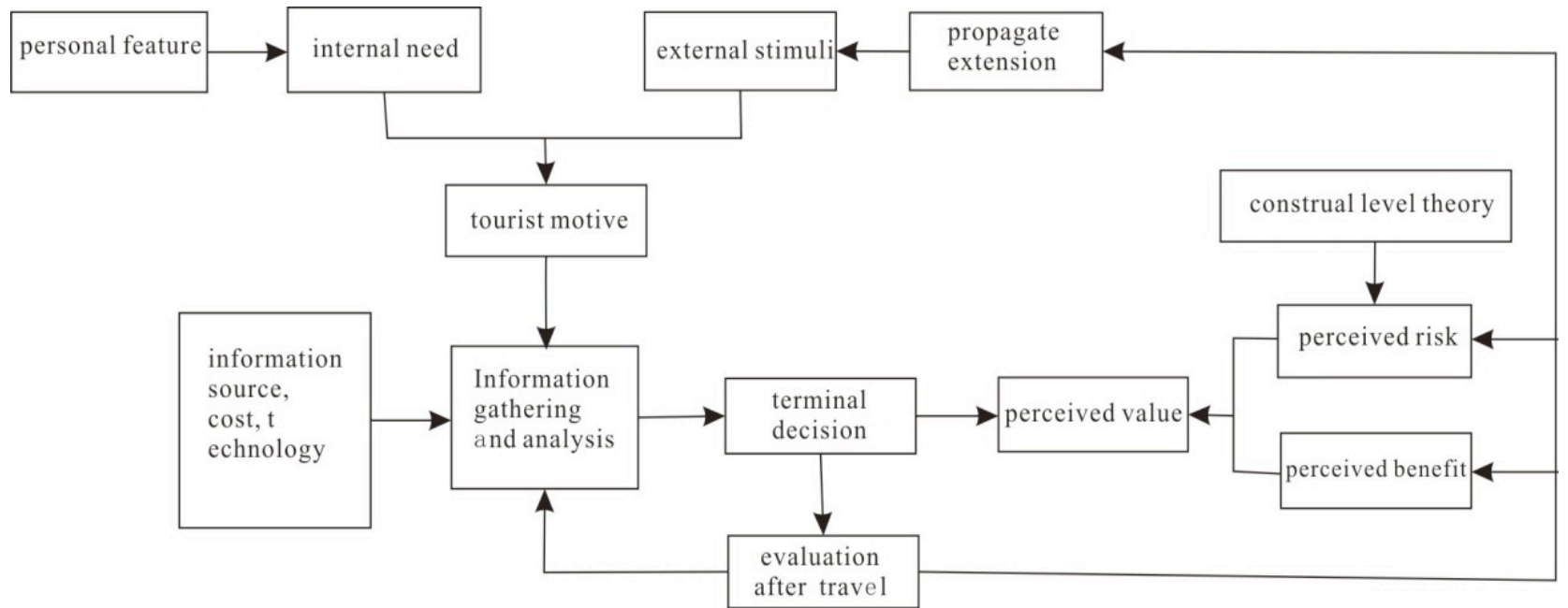

Fig. (1). The process of tourism decision-making.

demand for real commodity value which is a direct result of purchasing motivation, should be analysed, which is based on social needs, which can also lead to the motivation of online purchase. Perceptions of objective things are directly formed in the human brain. Consumers actions are influenced by their perception of objective things. Learning by experience causes changes in the individual's behavior. An individual's' learning is a driving force which stimulates reaction and strengthens the influence of interaction. At the same time, consumers through practice and learning and on the basis of their beliefs and attitudes can change their purchase decision.

\subsection{The Decision-Making Behavior of Tourists}

Tourism refers to the tourists' decision-making behavior about tourism destination choice behavior. As per the review of tourists' behavior research, the decision-making behavior of tourists is a key component of tourist behavior. Research content based on tourists behavior, future demand of tourism, tourism spatial structure, and the decisionmaking behavior of tourists is still relatively insignificant. Only in recent years domestic scholars began to pay close attention to this area. Scholars analysed tourist decisionmaking process, along with the factors influencing the decision-making behavior of tourists and tourism enterprises and market aspects of the studyand provided theoretical help and guidance.

\section{THE ANALYSIS ON INFLUENCING FACTORS OF TOURIST DECISION-MAKING}

Travel decisions initiate tourism activities. It is the joint action of internal factors and external factors of tourism determining the decision-making behavior of tourists themselves. Many factors affect tourists' travel decisions, which include tourists' motivation and purpose of tourism, tourists' psychological expectations, the type of tourist destination and the characteristics of different tourism activities which are the main factors affecting travel decisions.

Tourists' everyday working life, background and the environment, as well as their travel habits, are the key factors affecting the travel decisions. Different tourists, when deciding to participate in tourism activities, have different motives and choices. Travelling purpose is the concrete embodiment of tourist's motives and reflects the inner link between tourism motivation and tourism activities [10-12]. Tourist motives and purpose vary with personal characteristics, individual differences of age, professional background, income levels, and life experience. Working environment also greatly influences tourism motivation and purpose.

The psychological expectation before travelling is a subjective desire and requirement of tourist which strongly influence travel decisions. Tourists' psychological expectation and tourists' travelling experiences are influenced by the culture, health, and economic conditions and other external factors, such as public security. During the excursion, travel decisions are made based onthe psychological expectations of tourists by mainly considering safety in travelling.

The process of travel decision-making is divided into four stages: introduction of tourist's motives, collection analysis of information and the evaluation of final decision. Fig. (1) shows the tourism model representing the decisionmaking process. It can be seen from Fig. (1), that tourist motivation is influenced by the internal demand and external stimulation working together. Travel information source, information cost, and information technology are used for the analysis of applied to tourism information which affects the travel decisions. This process is important to evaluate once travel experience. . For ordinary tourists, travel decisions are made mainly on the basis of tourism motivation. Collection and analysis of information are key links for determining final decision.

In the age of Internet, users can now search and use information at a fast speed and with low cost. Internet has provided a wide range, of facilities which have, not only fundamentally changed the traditional way of information acquisition, but also solved the issues of low efficiency, small volume, and poor information comparability. On the basis of tourist information search services, tourism organization has been developed based on the Internet, which promotes the idea of travelling in groups. The development 
of the Internet is important for the enhancement of tourists travel decision-making.

\section{THE INTERNET TOURISM INFORMATION SER- VICE AND MANAGEMENT PATTERN}

\subsection{The Internet Tourism Information Technology Plat- form}

With the rapid popularization of Internet, the network has gradually become an important channel for obtaining information regarding tourists, services and products. Online travelling provides a variety of services and extremely attractive value-added services to customers to provide rich and colorful tourist service network. Efficient and high quality online travel service has made the tourism consumers enjoy a new tourism service, to people through online booking of tickets and hotels. In this way, a number of tourists enjoy the self-help travel services, and it also promotes Chinese tourism. In recent years, with the advent of blogs, micro blog and the development of the group buying websites, viewing online travel information has become a necessary step before the tourists' decision-making. According to Eire's research on the size of the market in 2010, China's online travel bookings showed an increased growth trend, and the online travel booking market size was 6.16 billion yuan, compared to 3.89 billion yuan in 2009 , which increased approx. 58.4\% from a year earlier. In 2011, three quarters of OTA market revenue reached 6.61 billion yuan, which was up to $41.5 \%$ from a year earlier.

The rapid development of the Internet tourism information service platform is the result of the technical advancement in tourism information service network. Internet tourism information service platform integrates hardware technology, software technology, network technology and other high and new scientific and technological achievements, in the form of a website or web page to provide information services to the user. According to the content of tourist information service platform and tourism activities, it can be divided into two categories; professional platform and common platform.

\subsection{The Tourism Service Supply Chain Management Pattern Based on Big Data}

With the continuous operation of tourism supply chain, the need to exchange and process data has also increased. Timely and economical efficient extraction of large scale data with high speed of data analysis is necessary to obtain effective information, . The main technical functions include real-time acquisition, classification, storage, semantic analysis and graphical transformation, pattern recognition, artificial intelligence, geographical information, statistical modeling, analysis, prediction, etc. Decision makers can not only utilize this data to understand the present scenario but can also use data to predict what will happen in the future, therefore, it helps them in taking relevant action to make active preparations.

In the process of travelling, data about tourists include each visitor's identity, location, time, preferences, aversion, and social relationships, which form a big packet of information. The data acquired is sent to data warehouse follow- ing non-relational data processing from the technical framework of heterogeneity. through data analysis. As an important part economic activity of tourism, coordination and cooperation in tourism supply chain make the economic activity comprehensive. A complete tourism supply chain should begin from thedemand analysis, combined with the construction of the model, followed by planning and management of earnings of the product. In addition, it also includes the evaluation of service, performance and feedback. The status of tourism supply chain is dynamic and is constantly updated due to the systematic accommodation of large data which plays an important role in the management of tourism supply chain. This paper is based on the research of large data model as shown in Fig. (2).

To provide complete introduction of the tourism products, and detailed analysis report, fortourism services to build a progressive intelligence service system, a variety of data is applied to the tourism supply chain . Cooperation between tourism enterprises of the traditional tourism supply chain is of central importance, while other enterprises make decisions and adjust themselves through cooperation. Tourism enterprises take advantage of large data information sharing and collaboration platform to improve the efficiency of industry services, to promote personalized and comprehensive development of service industry products. With large data as the carrier of synergy for the user's service demand, after matching and selection of the same link of combination of temporary tourism supply chain, these temporary supply chains correlate with each other and form a tourism supply network.

\section{THE INFLUENCE OF INTERNET ON TRAVEL DECISIONS ANALYSIS}

With the growing importance of Internet tourism information service, this article used a questionnaire to quantitatively investigate the influence of the Internet on the process of tourism decision-making .

\subsection{The Influence of Different Age Tourists' Decisions}

In the survey, it was found that different age groups of tourists were affected by different information on Internet. Most affection are " after 80 " people under the age of 30 and part of the crowd " after 90 " around the age of 20, most of them are students, there is plenty of time, but do not have enough disposable income, for network operation, familiar with the use of computer and Internet has penetrated into every aspect of life For all kinds of tourism information available on the Internet, tourists showed their own recognition and decision making skills . Before making decisions regarding travelling, they looked up all relevant information on the Internet and made full use of the Internet to access travel information to make good decisions, and also aimed to minimize the travel cost. People of middle-age (30 40 years old) and younger people had a fixed job and income, and were more familiar with how to use the network. More than half of the people used the network to comprehend the information relevant to their travelling which is shown in Table 1. Seven among 40 investigators did not use network resources, before the travel notes for network tourism infor- 


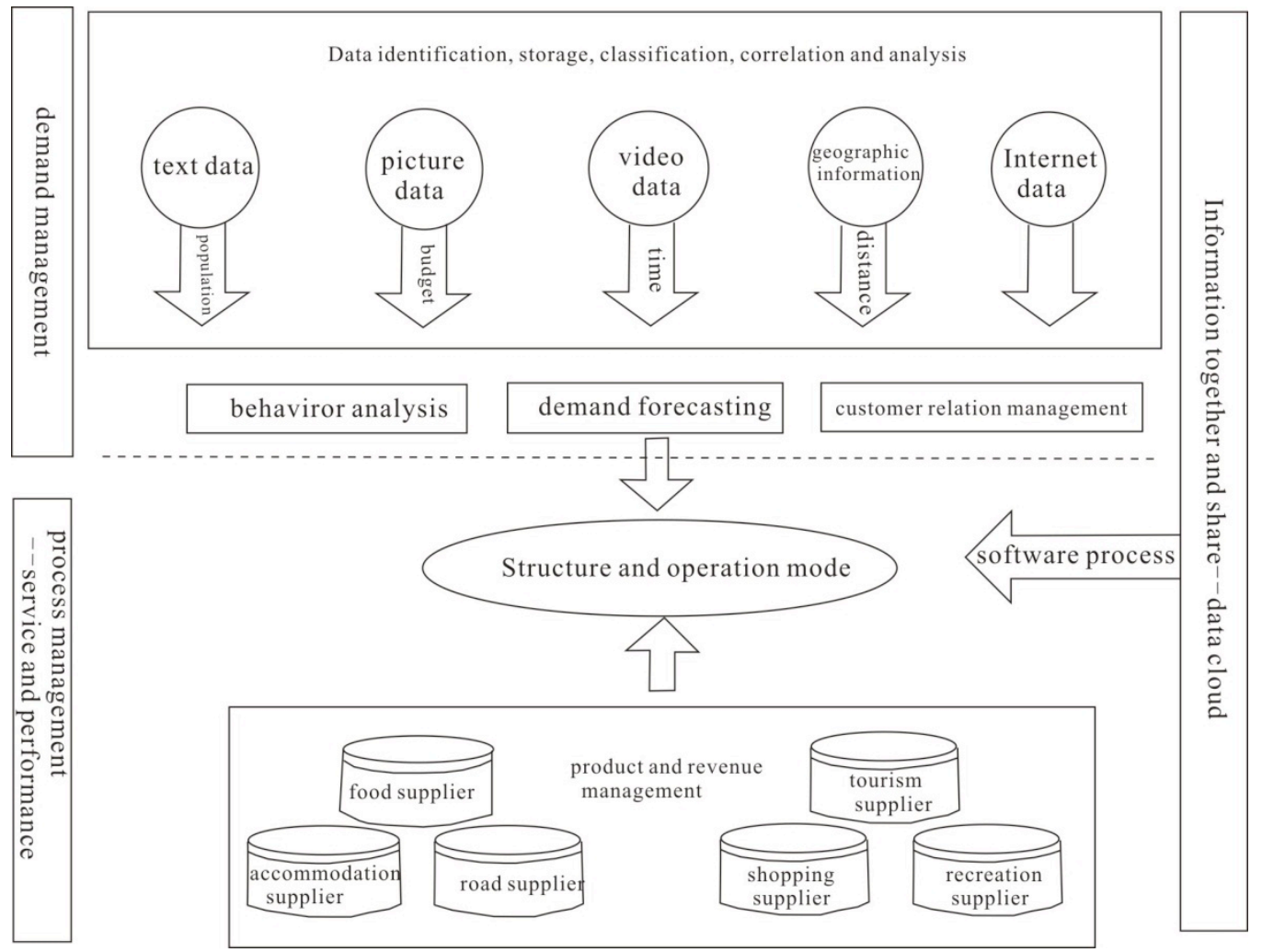

Fig. (2). The pattern of tourist service supply chai.

Table 1. The influence of internet for different age tourists.

\begin{tabular}{|c|c|c|c|c|c|}
\hline \multirow{2}{*}{ Age } & \multicolumn{3}{|c|}{ Whether Through the Internet to Learn About } & \multirow{2}{*}{ Total } & \multirow{2}{*}{$\begin{array}{c}\text { Affected by the Network } \\
(\%)\end{array}$} \\
\hline & Full & Little & No & & \\
\hline 19 years and below & 6 & 0 & 0 & 6 & 100 \\
\hline 20-24 years & 46 & 39 & 0 & 85 & 100 \\
\hline 25-29 years & 34 & 28 & 3 & 65 & 95.38 \\
\hline $30-40$ years & 7 & 3 & 3 & 13 & 76.92 \\
\hline 40 years and above & 0 & 0 & 7 & 7 & 0 \\
\hline total & 93 & 70 & 13 & 176 & \\
\hline
\end{tabular}

mation service in the elderly is strange, in tourism activities less use Internet search information.

\subsection{The Influence of Different Tourism Types}

In the questionnaire, according to the travel purpose, the tourism types were divided into the following categories: natural scenery tourism, historical and cultural tourism, health tourism, business travel, recreation tourism, and adventure tourism. The results of the questionnaire are shown in Table 2.

Statistics of the questionnaire survey showed that in various tourism types, tourism activity of individual freedom decision is influenced by the Internet is very large, such as natural scenery tourism, entertainment tourism, historical and cultural tourism, adventure tourism, etc., $90 \%$ of the tourists selected the type of tourism before making travel decision, in order to search the related information of their tourism destinations via the Internet, including traffic, accommodation, budget, tourist routes, tourist consumption during the weather conditions. etc. Because these types of travel facilities, tourists can take full advantage of the tourism services available on the Internet to have comprehensive grasp on the relevant information, to make suitable travel plans.

\subsection{The Influence of Different Organizations}

Tourism organization mode can be divided into travel agency, relatives and friends, individual travelling, and several group-buying travel networks. Statistical results of the questionnaire survey are shown in Table 3.

In the survey, of travel agency to travel, travel alone cases were more preferred than group travel. However, , relatives and friends were greatly influenced by network, relative to character, meeting less affected by the network. Alt- 
Table 2. The influence of internet for different tourism types.

\begin{tabular}{|c|c|c|c|c|c|}
\hline \multirow{2}{*}{ Tourism Types } & \multicolumn{3}{|c|}{ Whether Through the Internet to Learn About } & \multirow{2}{*}{ Total } & \multirow{2}{*}{$\begin{array}{l}\text { Affected by the } \\
\text { Network (\%) }\end{array}$} \\
\hline & Full & Little & No & & \\
\hline \multirow{7}{*}{$\begin{array}{c}\text { natural scenery tourism } \\
\text { historical and cultural tourism health tourism } \\
\text { business travel } \\
\text { recreation tourism } \\
\text { adventure tourism } \\
\text { total }\end{array}$} & 57 & 33 & 1 & 89 & 98.9 \\
\hline & 9 & 3 & 0 & 12 & 100 \\
\hline & 5 & 12 & 4 & 21 & 80.95 \\
\hline & 3 & 10 & 7 & 20 & 65 \\
\hline & 14 & 12 & 1 & 29 & 96.3 \\
\hline & 5 & 0 & 0 & 5 & 100 \\
\hline & 93 & 70 & 13 & 176 & 92.61 \\
\hline percentage & 52.84 & 39.77 & 7.39 & 100 & \\
\hline
\end{tabular}

Table 3. The influence of internet for different organizations.

\begin{tabular}{|c|c|c|c|c|c|}
\hline \multirow{2}{*}{ Organization Form } & \multicolumn{3}{|c|}{ Whether Through the Internet to Learn About } & \multirow{2}{*}{ Total } & \multirow{2}{*}{$\begin{array}{c}\text { Affected by the } \\
\text { Network (\%) }\end{array}$} \\
\hline & Full & Little & no & & \\
\hline The travel agency & 20 & 9 & 0 & 29 & 100 \\
\hline Meetings & 1 & 9 & 6 & 16 & 62.5 \\
\hline relatives and friends & 36 & 28 & 7 & 71 & 90.14 \\
\hline travel alone & 27 & 20 & 0 & 47 & 100 \\
\hline network group-buying travel & 9 & 4 & 0 & 13 & 100 \\
\hline total & 93 & 70 & 13 & 176 & 92.61 \\
\hline percentage & 52.84 & 39.77 & 7.39 & & \\
\hline
\end{tabular}

hough there are still many tourists who prefer the traditional travel agency offering sightseeing tour, however, when it comes to choosing a travel agency and tourism routes, most people prefer spending time on the network to seek information and support for their own tourism decision. They are of the view that in order to have a good travel experience, it is necessary to thoroughly search for information in advance, especially information regarding transportation, accommodation, travel site environment, cultural atmosphere and services of travel agency. In addition, tourists also hope that through network, they can get to know more about those who have been to those destinations and can evaluate the experiences of others who have travelled to China. Individual travelling and group travelling are relatively affordable ways of travelling. People in the 30 s age group preferred this kind of travelling and young people adopted a more independent and economical way to travel. They utilized network and quickly and conveniently gained tourism information by efficiently utilizing a progressive network information transmission means. This not only influenced the impact on the daily life of younger generation, but also had an impact on their choice of travelling.

\section{CONCLUSION}

Media as a source of information is the most important network and due to its unique advantage, it has become one of the main sources of dealing with most of the tourists' queries. Travel information available on the Internet has real-time efficiency, two-way interactivity, high capacity, convenience, safety and other characteristics. It also helps tourists in making proper travel decisions. At the same time in the process of communication in tourism, more practical information is obtained by other tourists, which provides help to the tourist for making travel decisions. Internet tourism in formation service has certain influence on tourism travel decision. Different age groups of tourists are differently influenced by the information available on the Internet, especially young and middle-aged travellers. The information available on the Internet helps in making different types of tourism travel decisions. In various types of tourism, natural scenery tourism, entertainment tourism, historical and cultural tourism, and adventure tourism, information on the Internet is utilized. At present, China's Internet tourism information service enterprise and platform are in rapid development, however, there are several existing problems. In-depth study and exploration of theInternet influence the development of tourism, to analyse the trend of the development in the tourism enterprises of our country.

\section{CONFLICT OF INTEREST}

The authors confirm that this article content has no conflict of interest. 


\section{ACKNOWLEDGEMENTS}

Declared none.

\section{REFERENCES}

[1] B. K. MeClery, "A model of destination image formation," Annals of TourismResearch, vol. 26, no. 4, pp. 868-897, 1999.

[2] C. Goossens, "Tourism Information and Pleasure Motivation," Annals of TourismReseareh, vol. 27, no. 2, pp. 301-321, 2000.

[3] X. Zhang, H. Song, and G. Q. Huang, "Tourism Supply Chain Management: A New Research Agenda," Tourism Management, vol. 30, no. 3, pp. 345-358, 2009.

[4] R. K. Lisa, "Evaluating the Potential of the Interactive Media through a New Lens: Search versus Experience Goods," Journal of Business Research, vol. 41, no. 3, pp. 195-203, 1998.

[5] Q. Su, G. Li, and Y. Cui, "Influence factor analysis and empirical study of Network consumer behavior," Journal Of Systems Engineering, vol. 2, pp. 1-6, 2007
[6] Y. Hu, and Z. Xiang, "From the Internet and e-commerce impact on the behavior of tourists see China hotel management," China's Tourism Research, vol. 2, pp. 100-120, 2005.

[7] M. Liang, and L. Wang, "Network tourism information investigation and analysis of the impact of tourist behavior patterns-in mount tai the tourists, for example," Journal Of Taishan College, vol. 1, pp. 83-87, 2008.

[8] J. Wen, and H. Gng, "Self-help tourists demand for network tourism information research," Journal of social sciences in Beijing, no. 4, pp. 61-66, 2009.

[9] P. Zheng, Y. Ma, and T. Li, "The influence factors of college students' attitude toward Internet tourism information form research," China's Tourism Research, vol. 9, pp. 47-53, 2009.

[10] T. Gao, "Internet media's influence on the youth travel decisions research," China Ocean University, 2010.

[11] $\mathrm{H} . \mathrm{Yu}$, "Network tourism information attitude influence on tourism decision-making research," Hunan Normal University, 2010.

[12] Y. Jiang, "The effects of Internet on college students' travel behavior research," China's New Technology, New Products, vol. 13, pp. 27-29, 2010.

(c) Liu et al.; Licensee Bentham Open.

This is an open access article licensed under the terms of the (https://creativecommons.org/licenses/by/4.0/legalcode), which permits unrestricted, noncommercial use, distribution and reproduction in any medium, provided the work is properly cited. 